03,08

\title{
Влияние легирования на свойства аморфного гидрогенизированного кремния, облученного фемтосекундными лазерными импульсами
}

\author{
(C) К.Н. Денисова, А.С. Ильин ", М.Н. Мартышов, А.С. Воронцов \\ Московский государственный университет им. М.В. Ломоносова, \\ Москва, Россия \\ ฯ E-mail: as.ilin@physics.msu.ru
}

(Поступила в Редакцию 13 фревраля 2017 г.)

\begin{abstract}
Проведен сравнительный анализ влияния фемтосекундного лазерного облучения на структуру и проводимость нелегированного и легированного бором аморфного гидрогенизированного кремния. Было обнаружено, что процесс образования нанокристаллов в аморфной матрице под действием фемтосекундного лазерного облучения для нелегированных образцов аморфного гидрогенизированного кремния начинается при меньших плотностях энергии лазерного излучения, чем для легированных образцов. Различная проводимость нелегированных и легированных образцов аморфного гидрогенизированного кремния до их фемтосекундного облучения становится примерно одинаковой при облучении с плотностями энергии $150-160 \mathrm{~mJ} / \mathrm{cm}^{2}$.
\end{abstract}

DOI: 10.21883/FTT.2018.04.45669.034

Гидрогенизированный аморфный кремний $(a-\mathrm{Si}: \mathrm{H})$ уже длительное время успешно используется для производства солнечных элементов, фотодетекторов и широкоформатных дисплеев. Один из главных недостатков $a-\mathrm{Si}: \mathrm{H}$ заключается в деградации его параметров под действием освещения [1]. Добиться более стабильных электрических и фотоэлектрических параметров позволяет создание в пленке аморфного кремния нанокристаллических включений [2-7]. Такие материалы (материалы, состоящие из аморфного кремния с включениями кристаллического кремния нанометрового размера) получили название нанокристаллический кремний $(n c-\mathrm{Si}: \mathrm{H})$ и достаточно широко исследуются в настоящее время [8-11]. Одним из способов получения $n c-\mathrm{Si}: \mathrm{H}$ является фемтосекундная лазерная кристаллизация $a-\mathrm{Si}: \mathrm{H}$ [12-15]. Этот метод позволяет локально кристаллизовать выбранные участки пленки $a-\mathrm{Si}: \mathrm{H}$, минимизировать эффузию водорода из пленки, а также проводить так называемую „холодную“ кристаллизацию, т. е. кристаллизовать пленки, расположенные в том числе на легкоплавких подложках.

На настоящий момент фемтосекундная лазерная кристаллизации $a$-Si:H достаточно подробно описана в литературе. В частности, имеются данные по влиянию фемтосекундного лазерного облучения пленок $a-\mathrm{Si}: \mathrm{H}$ на их структуру, содержание водорода, оптическое поглощение, проводимость и фотопроводимость [16-24]. Однако в литературе имеются данные по фемтосекундной лазерной кристаллизации нелегированного $a-\mathrm{Si}: \mathrm{H}$. В то же время для создания многих полупроводниковых приборов необходимы элементы как $p$-, так и $n$-типа, поэтому интересно рассмотреть влияние легирования на свойства $a$-Si:H, подвергнутого фемтосекундной лазерной кристаллизации. В данной работе проанализировано влияние легирования на объемную долю кристалличе- ской фазы и проводимость $a-\mathrm{Si}: \mathrm{H}$, подвергнутого фемтосекундной лазерной кристаллизации.

Две серии пленок аморфного гидрированного кремния толщиной $300 \mathrm{~nm}$ были получены методом плазмохимического осаждения моносилана $\left(\mathrm{SiH}_{4}\right)$ из газовой фазы на кварцевую подложку, покрытую слоем ITO. Температура кварцевой подложки составляла $250^{\circ} \mathrm{C}$. При получении образцов второй серии в реакционную камеру добавлялся также диборан $\left(\mathrm{B}_{2} \mathrm{H}_{6}\right)$, что приводило к легированию образцов бором. Объемное соотношение диборана к моносилану $\frac{\left[\mathrm{B}_{2} \mathrm{H}_{6}\right]}{\left[\mathrm{SiH}_{4}\right]}=10^{-4}$.

Полученные пленки обрабатывались фемтосекундными лазерными импульсами с помощью субтераваттного фемтосекундного комплекса на основе хромфорстеритового лазера. Длина волны излучения была равна $540 \mathrm{~nm}$, а длительность лазерных импульсов составляла $500 \mathrm{fs}$. Облучение проводилось путем сканирования лазерным лучом поверхности пленки. Скорость сканирования $v=5 \mathrm{~mm} / \mathrm{s}$, частота повторения падающих на образец импульсов $v=200 \mathrm{kHz}$. Лазерное излучение фокусировалось на образец с помощью асферической стеклянной линзы с числовой апертурой 0.16. Фокальная плоскость была помещена на расстоянии $80 \mu \mathrm{m}$ над поверхностью образца. Обозначения образцов первой и второй серии и значения плотности энергии использованного лазерного излучения представлены в табл. 1.

Измерения спектров комбинационного рассеяния света проводилось на спектрометре LabRam HR800 „Horiba Jobin Yvon“. Возбуждение образцов осуществлялось светом с длиной волны $632.8 \mathrm{~nm}$.

Для определения проводимости образцов на их поверхность напылялись алюминиевые контакты площадью $1 \mathrm{~mm}^{2}$. Нижним контактом служила пленка ITO, нанесенная на подложку. Для измерения проводимости 
Таблица 1. Обозначения образцов первой и второй серии и значения плотности энергии использованного лазерного излучения

\begin{tabular}{c|c|c|c}
\hline $\begin{array}{c}\text { № образца } \\
\text { первой серии }\end{array}$ & $\begin{array}{c}\text { Плотность энергии } \\
\text { лазерного излучения, } \mathrm{mJ} / \mathrm{cm}^{2}\end{array}$ & $\begin{array}{c}\text { № образца } \\
\text { второй серии }\end{array}$ & $\begin{array}{c}\text { Плотность энергии } \\
\text { лазерного излучения, } \mathrm{m} / \mathrm{cm}^{2}\end{array}$ \\
\hline $1-1$ & 160 & $2-1$ & 150 \\
$1-2$ & 120 & $2-2$ & 710 \\
$1-3$ & 80 & $2-3$ & 50 \\
$1-4$ & 60 & $2-4$ & 30 \\
$1-5$ & 40 & $2-5$ & 0
\end{tabular}

Таблица 2. Значения доли кристаллической фазы и размера нанокристаллов для образцов серий 1 и 2

\begin{tabular}{c|c|c|c|c|c}
\hline \multicolumn{2}{c|}{$\begin{array}{c}\text { 1 серия } \\
a \text {-Si:H }\end{array}$} & \multicolumn{2}{c}{$\begin{array}{c}2 \text { серия } \\
a \text {-Si:H(B) }\end{array}$} \\
\hline $\begin{array}{c}\text { № } \\
\text { образца }\end{array}$ & $\begin{array}{c}\text { Размер } \\
\text { нанокристаллов, nm }\end{array}$ & $\begin{array}{c}\text { Доля } \\
\text { крист. фазы, } X_{c}, \%\end{array}$ & $\begin{array}{c}\text { № } \\
\text { образца }\end{array}$ & $\begin{array}{c}\text { Размер } \\
\text { нанокристаллов, nm }\end{array}$ & $\begin{array}{c}\text { Доля } \\
\text { крист. фазы, } X_{c}, \%\end{array}$ \\
\hline $1-1$ & 6 & 22 & $2-1$ & 4 & 7 \\
$1-2$ & 6 & 14 & $2-2$ & 4 & 5 \\
$1-3$ & 6 & 3 & $2-3$ & - & 0 \\
$1-4$ & - & 0 & $2-4$ & - & 0 \\
$1-5$ & - & 0 & $2-5$ & - & 0 \\
$1-6$ & - & 0 & $2-6$ & - & 0
\end{tabular}

пленок использовался пикоамперметр Keithley 6487. Измерения проводились при комнатной температуре.

Спектры комбинационного рассеяния света для пленок первой и второй серии представлены на рис. $1, a, b$ соответственно. Объемная доля кристаллической фазы и размер нанокристаллов определялись из анализа спектров комбинационного рассеяния согласно процедуре, описанной в работах [25-27].
Определенные из спектров комбинационного рассеяния света значения объемной доли кристаллической фазы и размеры нанокристаллов для двух исследованных серий образцов приведены в табл. 2.

Из приведенных в табл. 2 данных видно, что в нелегированных пленках $a$-Si:H нанокристаллы образуются при плотности энергии лазерного облучения $80 \mathrm{~mJ} / \mathrm{cm}^{2}$ и объемная доля кристаллической фазы может дости-
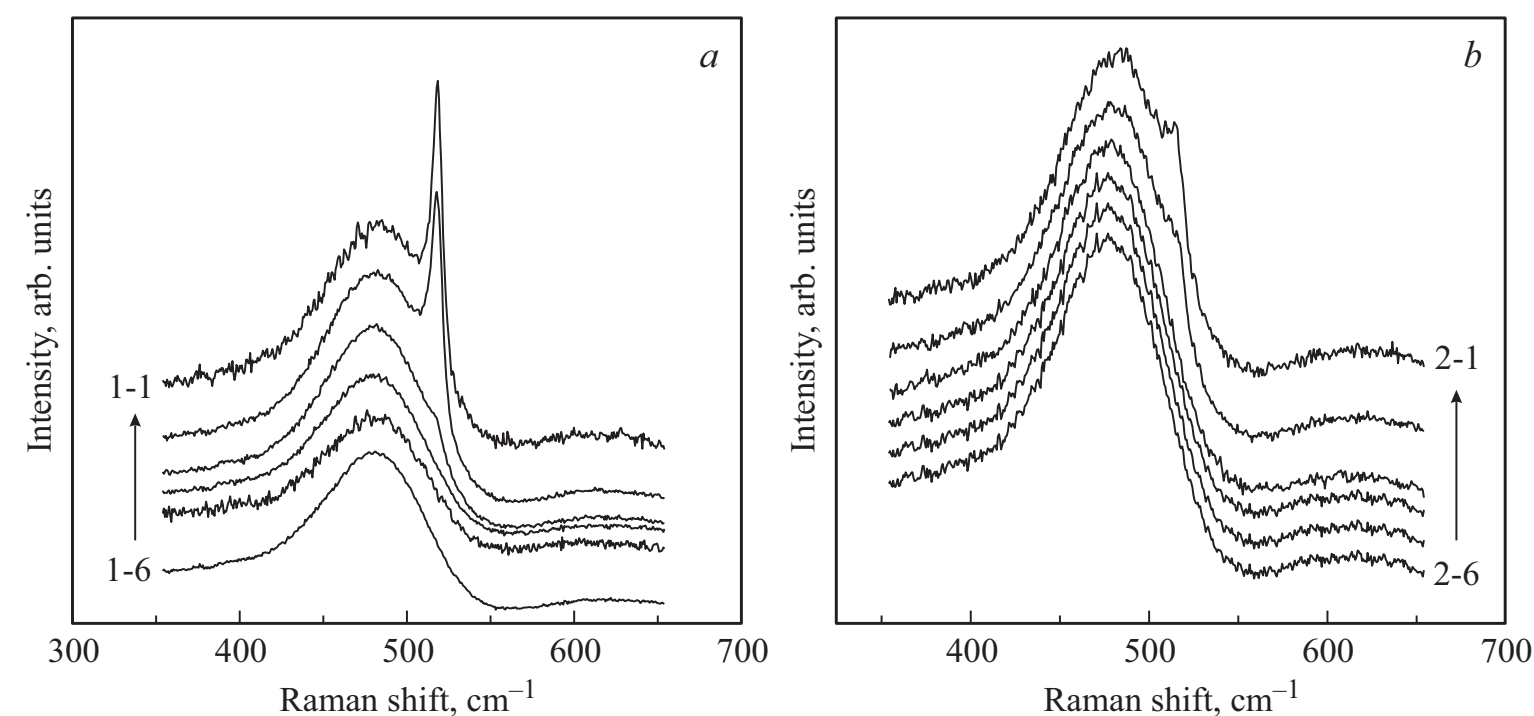

Рис. 1. Спектры комбинационного рассеяния света для образов первой серии $a$ и второй серии $b$. Цифрами обозначены номера образцов, которые соответствуют крайним спектрам. Стрелкой на графике показано направление увеличения плотности энергии лазерного излучения. 


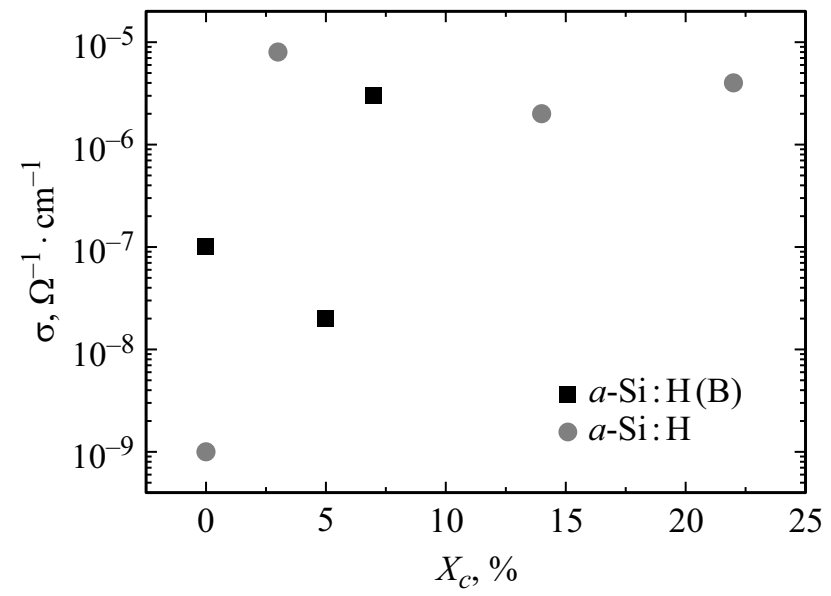

Рис. 2. Зависимость проводимости образцов от объемной доли кристаллической фазы для образцов серии $1(a-\mathrm{Si}: \mathrm{H})$ и $2(a-\mathrm{Si}: \mathrm{H}(\mathrm{B}))$.

гать 22\%. В то время как в легированных пленках кристаллизация начинается только при $110 \mathrm{~mJ} / \mathrm{cm}^{2}$, и доля кристаллической фазы не превышает 10\%. На данный момент невозможно однозначно судить о причинах такого различия. Однако можно отметить, что согласно работам [28-30] наилучшие с точки зрения использования в солнечной энергетике параметры демонстрируют образцы $n c-\mathrm{Si}: \mathrm{H}$ с объемной долей кристаллической фазы менее $10 \%$ и размером нанокристаллов 3-7 nm. При фемтосекундной лазерной кристаллизации аморфного гидрогенизированного кремния, легированного бором, именно такие образцы и получаются. Поэтому можно сказать, что фемтосекундная лазерная кристаллизация легированного бором аморфного кремния позволяет получать материал, перспективный для использования в солнечной энергетике.

Перейдем к сравнению проводимости легированных и нелегированных пленок аморфного кремния, подвергнутых фемтосекундной лазерной кристаллизации. На рис. 2 показана зависимость проводимости от объемной доли кристаллической фазы для образцов первой и второй серий.

Как видно из рисунка, до облучения лазерными импульсами проводимость легированной пленки на 2 порядка превышала проводимость нелегированного $a-\mathrm{Si}: \mathrm{H}$. Затем при обработке образцов лазером, с ростом плотности энергии излучения наблюдался немонотонный рост проводимости для обеих серий, но проводимость серии 1 возрастает на 4 порядка, тогда как для серии 2 рост составляет 1-2 порядка. При максимальных использованных плотностях энергии лазерного излучения проводимости $a-\mathrm{Si}: \mathrm{H}$ и $a-\mathrm{Si}: \mathrm{H}(\mathrm{B})$ становятся примерно одинаковыми. Следует отметить, что поскольку для измерения проводимости использовалась вертикальная конфигурация расположения электрических контактов, а расстояние между контактами было мало (равно толщине пленки, $500 \mathrm{~nm}$ ), нельзя исключать возможность проникновения алюминия (из которого были сделаны контакты) вглубь пленки. Это могло приводить к ошибкам в определении проводимости.

Таким образом, в нелегированных пленках $a-\mathrm{Si}: \mathrm{H}$ нанокристаллы образуются при плотности энергии лазерного облучения $80 \mathrm{~mJ} / \mathrm{cm}^{2}$ и объемная доля кристаллической фазы может достигать значений более $20 \%$. В то время как в легированных бором пленках кристаллизация начинается только при $110 \mathrm{~mJ} / \mathrm{cm}^{2}$ и доля кристаллической фазы не превышает $10 \%$. Можно предположить, что наличие бора влияет на механизм лазерной кристаллизации. В то же время малая объемная доля кристаллической фазы (менее 10\%) при фемтосекундной лазерной кристаллизации легированного бором аморфного кремния указывает на возможность получения материала, перспективного для использования в солнечной энергетике.

До облучения фемтосекундными лазерными импульсами проводимость легированных бором пленок аморфного кремния на 2 порядка превышает проводимость нелегированного $a-\mathrm{Si}: \mathrm{H}$, но проводимость $a-\mathrm{Si}: \mathrm{H}(\mathrm{B})$ испытывает меньший рост с увеличением плотности энергии лазерного излучения. Проводимость двух видов образцов становится примерно одинаковой, при облучении с плотностями энергии $150-160 \mathrm{~mJ} / \mathrm{cm}^{2}$.

\section{Список литературы}

[1] D.L. Staebler, C.R. Wronski. J. Appl. Phys. 51, 3262 (1980).

[2] C.R. Wronski, R.W. Collins. Solar Energy, 77, 877 (2004).

[3] M.Y. Soro, M.E. Gueunier-Farret, J.P. Kleider. J. Appl. Phys. 109, 023713 (2011).

[4] J.P. Kleider, P. Roca i Cabarrocas. J. Non-Cryst. Solids 299-302, 599 (2002).

[5] А.Г. Казанский, П.А. Форш, Е.И. Теруков, J.P. Kleider. ФТП 44, 513 (2010).

[6] P.A. Forsh, A.G. Kazanskii, H. Mell, E.I. Terukov. Thin Solid Films 383, 251 (2001).

[7] M.V. Chukichev, P.A. Forsh, W. Fuhs, A.G. Kazanskii. J. NonCryst. Solids 338-340, 378 (2004).

[8] K. Lips, P. Kanschat, D. Will, C. Lerner, W. Fuhs. J.Non-Cryst. Solids 227-230, 1021 (1998).

[9] G. Juska, K. Arlauskas, N. Nekrasas, J. Stuchlik, X. Niquille, N. Wyrsch. J. Non-Cryst. Solids 299-302, 375 (2002)

[10] А.Г. Казанский, Х. Мелл, Е.И. Теруков, П.А. Форш. ФТП 34, 373 (2000).

[11] П.А. Форш, Л. А. Осминкина, В.Ю. Тимошенко, П.К. Кашкаров. ФТП 38, 626 (2004).

[12] S.D. Sundaram, E. Masur. Nature. Mater. 1, 217 (2002).

[13] J. Shieh, Z. Chen, B. Dai, Y. Wang, A. Zaitzev, C. Pan. Appl. Phys. Lett. 85, 1232 (2004).

[14] X.C. Wang, H.Y. Zheng, C.W. Tan, F. Wang, H.Y. Yu, K.L. Pey. Opt. Express 18, 19379 (2010).

[15] B.K. Nayak, M.C. Gupta. Appl. Phys. A 89, 663 (2007).

[16] А.В. Емельянов, А.Г. Казанский, П.А. Форш, М.В. Хенкин, П.К. Кашкаров, О.И. Коньков, А.В. Кукин, Е.И. Теруков, M. Beresna, P. Kazansky. ФТП 46, 769 (2012).

[17] V.A. Volodin, A.S. Kachko, A.G. Cherkov, A.V. Latyshev, J. Koch, B.N. Chichkov, A.Y. Rhozanov. JETP Lett. 93, 665 (2011). 
[18] В.А. Володин, А.С. Качко. ФТП 45, 268 (2011).

[19] A.V. Emelyanov, A.G. Kazanskii, M.V. Khenkin, P.A. Forsh, P.K. Kashkarov, M. Gecevicius, M. Beresna, P.G. Kazansky. Appl. Phys. Lett. 101, 081902 (2012).

[20] M.V. Khenkin, D.V. Amasev, A.O. Dudnik, A.V. Emelyanov, P.A. Forsh, A.G. Kazanskii, R. Drevinskas, M. Beresna, P. Kazansky. J. Nanoelectron. Optoelectron. 9, 728 (2015).

[21] А.В. Емельянов, А.Г. Казанский, П.К. Кашкаров, О.И. Коньков, Н.П. Кутузов, В.Л. Лясковский, П.А. Форш, М.В. Хенкин. Письма в ЖТФ, 40, 1 (2014).

[22] A.V. Emelyanov, M.V. Khenkin, A.G. Kazanskii, P.A. Forsh, P.K. Kashkarov, M. Gecevicius, M. Beresna, P.G. Kazansky. Thin Solid Films, 556, 410 (2014).

[23] M. Khenkin, A. Emelyanov, A. Kazanskii, P. Forsh, M. Beresna, M. Gecevicius, P. Kazansky. Can. J. Phys. 92, 883 (2014).

[24] А.В. Емельянов, П.А. Перминов, П.А. Форш, С.В. Заботнов, А.Г. Казанский, М.В. Хенкин, П.К. Кашкаров. Наноматериалы и нанотехнологии 1, 40 (2012).

[25] A.V. Emelyanov, A.G. Kazanskii, P.A. Forsh, D.M. Zhigunov, M.V. Khenkin, N.N. Petrova, A.V. Kukin, E.I. Terukov, P.K. Kashkarov. J. Nanoelectron. Optoelectron. 10, 649 (2015).

[26] М.В. Хенкин, А.В. Емельянов, А.Г. Казанский, П.А. Форш, П.К. Кашкаров, Е.И. Теруков, Д.Л. Орехов, Р. Roca i Cabarrocas. ФТП, 47, 1283 (2013).

[27] А.В. Емельянов, Е.А. Константинова, П.А. Форш, А.Г. Казанский, М.В. Хенкин, Н.Н. Петрова, Е.И. Теруков, Д.А. Кириленко, Н.А. Берт, С.Г. Конников, П.К. Кашкаров. Письма в ЖЭТФ 97, 536 (2013).

[28] М.В. Хенкин, А.В. Емельянов, А.Г. Казанский, П.К. Кашкаров, П.А. Форш. Вест. РГРТУ 42, 47 (2012).

[29] А.Г. Казанский, Е.И. Теруков, П.А. Форш, М.В. Хенкин. ФТП 45, 518 (2011).

[30] P. Roca i Cabarrocas, A. Fontcuberta i Morral, Y. Poissant. Thin Sol. Films 403-404, 39 (2002). 